CIENCIA Y SOCIEDAD

Volumen XXV, Número 4

Octubre - Diciembre 2000

EL FASCINANTE MUNDO DE LOS LIBROS

José Alcántara Almánzar

\title{
RESUMEN
}

Desde tiempos relativamente cercanos en la historia de la humanidad, el libro ha servido como instrumento privilegiado de difusión cultural, porque él recoge las ideas que han transformado al mundo en cada período crucial de su devenir. El libro ha sido uno de los más útiles objetos en la acumulación de la cultura, un proceso que se inició a pasos lentos en la prehistoria del género humano y que ha cobrado una celeridad vertiginosa en el útlimo siglo.

Un serio problema del proceso educativo nacional que se refleja en toda su crudeza durante los años universitarios, es la resistencia de los estudiantes a la lectura de textos de índole filosófica, histórica, sociológica o literaria que resultan indispensables para una buena formación académica. Sin una sólida base humanística, queda siempre trunca y deformada la carrera del profesional de las ciencias y la tecnología.

Cuesta mucho vencer la esclerosis mental de los alumnos que ingresan a las aulas universitarias y es preciso un esfuerzo titánico para estimularlos a leer. La primera dificultad consiste en la falta de motivación, la ignorancia y el paupérrimo vocabulario, que en un estudiante de último año de bachillerato se reduce a unos cuantos centenares de palabras.

A lo largo de este ensayo, el autor explica la importancia de la lectura en la formación estudiantil y los retos que tienen ante sí la familia y la escuela para contribuir a la formación integral del ser humano. Además, ofrece una serie de recomendaciones de lectura para quienes se inician en el fascinante mundo de los libros.

\footnotetext{
$\therefore$ Profesor del INTEC
} 


\section{EL MUNDO DE LOS LIBROS}

Como todo el mundo, sólo tengo a mi servicio tres medios para evaluar la existencia humana: el estudio de mí mismo, que es el más dificil y peligroso, pero también el más fecundo de los métodos; la observación de los hombres, que logran casi siempre ocultarnos sus secretos o hacernos creer que los tienen; $y$ los libros, con los errores de perspectiva que nacen entre sus líneas.' Estas certeras palabras, que Marguerite Yourcenar pone en boca del emperador Adriano en alguna página de su obra maestra Memorias de Adriano, revelan los prodigiosos atributos del libro como fuente de conocimiento ontológico.

Desde tiempos relativamente cercanos en la historia de la humanidad -hablo del siglo XV, cuando Guttenberg perfeccionó la imprenta con la invención de los caracteres móviles de metal, haciendo posible la multiplicación de la letra impresa-. el libro ha servido como instrumento privilegiado de difusión cultural, porque él recoge las ideas que han transformado al mundo en cada período crucial de su devenir. Como ha dicho nuestro Manuel Rueda en un artículo titulado "El libro: magia y realidad": "...todo lo que la humanidad ha pensado, creido y sentido se encuentra, como por arte de magia, en los libros: Y es cierto que en ellos se encuentra una magia particular que ningún otro objeto posee. Si vistos en sus anaqueles parecen momias polvorientas. basta el hecho de tomarlos y abrirlos en una página cualquiera para que surjan de inmediato, al calor de la vida, pueblos enteros con sus culturas, sentimientos heroicos o delicados, todo el vórtice natural de las pasiones, la fuerza de la naturaleza y la intimidad del ser humano, mostrada en las fluctuaciones de la Lengua y en las peripecias del estilo."

Marguerite Yourcenar. Memorias de Adriano. México. Lditorial l Hermes, 1986. 8va reimp. p.30

= Manuel Rueda. "Una voz", Isla Abierta. Hoy. No.759, 3-10-99. p.2. 
En los libros, pues, hallamos ese hermoso caos que constituyen las experiencias de millones de hombres y mujeres, el fervor doctrinario que anima a los creyentes, el resplandor filosófico que asoma en cada teoría, la incertidumbre del que duda, las convicciones del luchador, la descripción de todas las peripecias del explorador y el aventurero en regiones ignotas habitadas por pueblos de costumbres insólitas, las vicisitudes padecidas en la guerra, las bondades y progresos de las épocas de paz, las grandezas de los héroes y los mártires, las miserias de los oprimidos, la generosidad de los justos, las infamias de los viles, el vuelo de la imaginación y la fantasía proyectado hacia dimensiones desconocidas, y, en fin, el poder siempre creador de la palabra, múltiple e infinita, que nos permite construir mundos insospechados e inventar nuevas realidades.

El libro ha sido uno de los más útiles objetos en la acumulación de la cultura, un proceso que se inició a pasos lentos en la prehistoria del género humano y que ha cobrado una celeridad vertiginosa en el último siglo. Pensemos en el atraso de la humanidad sin el valioso auxilio de esa memoria colectiva estructurada con caracteres tipográficos tan diversos como los millares de idiomas y dialectos que inundan el planeta con la elocuencia de sus signos.

Los libros capitales que han marcado el curso de la historia no cesan de cambiar con el paso de los años. Cada lectura de esos libros esenciales es una lectura diferente. La Ilíada y La Odisea. La Divina Comedia, El Ingenioso Hidalgo don Quijote de la Mancha, El doctor Fausto, Madame Bovary, Crimen y castigo. Guerra y paz, En busca del tiempo perdido, La montaña mágica, Contrapunto y La metamorfosis, por sólo citar un puñado de obras maestras desde Homero hasta Kafka, constituyen ejemplos cimeros de esta afirmación. En cada época se encuentran nuevas facetas en el múltiple sentido que nos ofrecen las palabras ordenadas en un texto. Cada generación, con su sensibilidad particular, sus preocupaciones específicas y su manera de ver y asumir 
la vida, descubre dimensiones que otras no habían visto antes, o en las que no habían reparado.

El libro está siempre aguardando al lector, discreto y silencioso en el estante, la mesa de noche, o el anaquel de la biblioteca, presto a satisfacer nuestras necesidades cognoscitivas en cualquier momento, dispuesto a entregarnos sus secretos sin ponernos ninguna condición; ajeno por completo, en su aparente quietud y mansedumbre, a las motivaciones que nos empujan a tomarlo en nuestras manos y hojear cada página buscando lo que anhelamos encontrar, deteniéndonos en el pasaje clave, en las ideas fundamentales, deleitándonos con los primores de un estilo o las genialidades de un escritor.

El libro se convierte así en consejero prudente en el amor, el poder político, las relaciones económicas, las creencias religiosas y el comportamiento moral. La Biblia ha sido, por ejemplo, el libro sagrado del pueblo hebreo y la obra fundamental del cristianismo durante milenios, guía de creyentes en cosas humanas y divinas. Pero hay casos en que el libro es un temible agitador, un incendiario que desencadena las enormes marejadas de la voluntad popular galvanizada en torno a unos cuantos ideales y aspiraciones. Recordemos los efectos políticos que tuvo el Manifiesto comunista de Marx y Engels sobre la sociedad europea en la segunda mitad del siglo pasado. Publicado en 1848, este breve panfleto dirigido a estimular la lucha obrera contra la burguesía en el poder, bajo el lema: "Proletarios de todo el mundo, uníos", transformó por completo la configuración ideológica, política y social del mundo en menos de un siglo.

A veces el libro se muestra como un sabio maestro, portador de todos los conocimientos y todas las soluciones, un salvador que viene a resolver los problemas apremiantes y a contestar las preguntas difíciles; es el caso de los libros escritos por esa amplia gama de seres providenciales, místicos o no, que pretenden sacarnos de las tinieblas para llevarnos a una zona luminosa. 
En otras ocasiones, el libro cumple una función trastornadora, inquietante. provocativa. Hace tambalear nuestras creencias más firmes y nos pone al borde de cataclismos espirituales que somos incapaces de evitar. En el instante menos esperado se produce un vuelco interior, el chispazo del alumbramiento, y el libro llega a provocar en el lector una portentosa mutación espiritual y mental. Y todo esto con palabras. ¿Cuántas personas han cambiado su modo de ver el mundo después de la lectura de obras como $E l$ paraiso perdido de Milton, El Príncipe de Maquiavelo, o El arte de la prudencia de Gracián? ¿O, más modernamente, La rebelión de las masas de José Ortega y Gasset, y Tiempo nublado de Octavio Paz?

Pero el libro también es fiesta, diversión y regocijo que hace reír a carcajadas, o sonreír discretamente mientras induce a pensar en las cosas más graves que acontecen en nuestras vidas, como ocurre en las obras de Lewis Carroll o Mark Twain. El libro, en su sólida estructura de páginas y tapas ilustradas, también recrea el espíritu al tiempo que sondea y refleja la condición humana. Amigo silencioso, consejero fiel, soldado de las buenas causas, taumaturgo del saber, el libro es la mejor compañía en los momentos de soledad y de ocio bien empleado.

\section{EL. PROBLEMA DE LA LECTLRA}

Un serio problema del proceso educativo nacional que se refleja en toda su crudeza durante los años universitarios, es la resistencia de los estudiantes a la lectura de textos de índole filosófica, histórica, sociológica o literaria que resultan indispensables para una buena formación académica. Sin una sólida base humanística, queda siempre trunca y deformada la carrera del profesional de las ciencias y la tecnología. Ese profesional obtiene su título al cabo de un lapso de cuatro o cinco años de esfuerzo, pero seguirá siendo un analfabeto funcional en muchas dimensiones de su vida. Aunque maneje los instrumentos de trabajo 
de su especialidad, carece de visión para aplicar correctamente sus conocimientos, se muestra incapaz de relacionarse en forma adecuada con su medio social y cultural, y no puede retribuir a la sociedad lo que ésta invirtió en su formación. Sé de muchos diplomados en la universidad que nunca leen un libro, ni siquiera revistas o periódicos para enterarse de lo que pasa en sus profesiones o en el mundo.

Cuesta mucho vencer la esclerosis mental de los alumnos que ingresan a las aulas universitarias y es preciso un esfuerzo titánico para estimularlos a leer. La primera dificultad consiste en la falta de motivación, la ignorancia y el paupérrimo vocabulario. que en un estudiante de último año de bachillerato se reduce a unos cuantos centenares de palabras. Los textos se convierten entonces en una abstrusa red en la que es imposible penetrar, un complicado amasijo de palabras de difícil comprensión. El estudiante, desalentado ante tantos términos raros, sin ninguna práctica en el uso sistemático del diccionario. termina dejando la lectura en las primeras líneas del texto. Imaginemos la tortura que debe padecer un estudiante de literatura española cuando se enfrenta con un poema de Góngora o un drama de Calderón de la Barca. Sin embargo, las dificultades léxicas del autor de las Soledades pueden ser vencidas con un buen procedimiento para acceder a la esencia de sus versos. De igual modo, la profundidad existencial de una obra como La vida es sueño puede llegar a convertirse en un desafío apasionante.

El segundo escollo es la incapacidad para determinar qué es lo esencial, cuáles son las ideas motrices. cómo se articulan con las secundarias. En este punto, lo más complicado es precisamente aprehender lo fundamental donde todo parece importante. Esta barrera, más que de simple lógica, proviene del poco entrenamiento para seguir la línea temática en un texto, poniendo cada cosa en su lugar hasta llegar a distinguir entre lo básico y lo complementario. 
En tercer término está la extensión de las lecturas. Hay un verdadero pánico a cualquier texto que exceda un cierto número de páginas, y la pregunta que de inmediato surge cuando un profesor asigna un texto no es sobre el contenido o los aspectos formales, sino acerca de su amplitud. En lugar de acudir al original de El Quijote -libro que muchos proclaman como fundamental sin haberlo leído nunca--, el estudiante se contenta con un resumen que degrada y traiciona el espíritu de la obra.

A propósito de ese libro verdaderamente prodigioso y fundacional que es El Quijote, deseo precisar algo sobre las obras maestras de los grandes clásicos universales. Cuando un libro tiene varios siglos de escrito (y Cervantes escribió su obra cumbre entre 1606 y 1616, es decir, hace casi cuatro siglos), nos enfrenta a dificultades de lectura particulares que de ningún modo resultan insalvables. Ha habido un cambio en el lenguaje, porque la lengua es dinámica y se transforma constantemente. Pero la grandeza de un libro como ése, e igual ocurre con los dramas de Shakespeare, llámense Hamlet, Otello, Macheth o El Rey Lear, reside precisamente en vencer las adversidades del tiempo. Hay valores universales inmanentes, como el bien, la justicia, la solidaridad, la libertad, que logran traspasar las fronteras epocales. deslizándose por encima de las huellas que dejan a su paso las mutaciones generacionales.

No es cierto que un clásico antiguo, por el hecho de haber escrito un libro o haber compuesto música hace cientos de años, pierda su atractivo para el lector o el oyente contemporáneos. Si nos trasladamos al campo de la música encontramos, por ejemplo, que Johann Sebastian Bach es hoy más moderno que nunca, e incluso algunos críticos han llegado a considerarlo como un romántico, habiendo sido, con toda propiedad, el gran maestro del barroco. Bastaría sólo con mecionar El clave bien temperado. auténtico producto de su genio, para colocarlo entre los padres de la música universal. El caso de Beethoven es otro ejemplo 
contundente de actualidad. Fue un revolucionario en su tiempo y sigue siendo un modelo para cuantos acuden a su obra en busca de rigor, perfección e innovación constante. Sus sinfonías, sus sonatas para piano, y en especial sus cuartetos para cuerdas, prueban con creces la actualidad de su legado musical.

En lo que a la literatura se refiere, una obra debe explorarse con ojos nuevos y prestos a descubrir los sécretos que ella encierra. Si la maestra o el profesor son buenos guías y saben motivar y conquistar, porque son también buenos lectores y aman los libros y las palabras, no habrá quien se resista a la pasión de leer.

Sin embargo, desalentados por su incapacidad para enfrentarse a cualquier tipo de lectura, el estudiante vive atormentado y la frustración no tarda en aparecer, conduciéndolo no pocas veces a la deserción y al fracaso.

Me he preguntado muchas veces si la causa de esta indisposición y desinterés es provocada por la invasión de los medios televisivos en los hogares y en el creciente uso de juegos que envician al espectador, encadenándolo a un aparato. sin darle tregua para dedicarse a la lectura, actividad que requiere una postura nada pasiva. No descarto que, en algunos casos, la distracción causada por la televisión y los juegos electrónicos sea la causante de los bajos rendimientos escolares, no sólo de niños. sino también de jóvenes y adultos. Pero creo que la causa fundamental de este rechazo hay que buscarla en la educación básica y los niveles siguientes, que es donde se forman los hábitos y se estructura la disciplina que debe puseer todo estudiante para conducir sus asuntos con un mínimo de eficiencia.

Durante sus primeros cursos, el niño lo único que hace es copiar y memorizar. Allí aprende a recitar muy mal los resúmenes y las tareas, sin penetrar demasiado en el núcleo del conocimiento. Es un saber fragmentario, atomizado, que el infante es incapaz de aplicar debidamente en el desarrollo de un hábito de lectura que le ayude a consolidar su formación. En los cursos que 
van de quinto a octavo (segundo ciclo del nivel básico) continúa la situación, coloreada de anecdotarios. moralejas y simples recuentos, sin que el joven sepa que lo verdaderamente importante es amar las palabras, aprender a manejarlas, adquirir fluidez en la lectura y la escritura, que constituyen instrumentos primordiales en el proceso de comunicación. Nunca llega a hacerse realidad la bella frase de Marguerite Yourcenar: "El verdadero lugar de nacimiento es aquel donde por primera ve $z$ nos miramos con una mirada inteligente: mis primeras patrias fueron los libros."

Así llega el joven al bachillerato (nivel medio), donde se las arregla con los tristemente famosos temarios. que van convirtiendo su mente en un depósito atiborrado de informaciones y datos aislados, sin ninguna relación ni concierto. En bachillerato -lapso en que los jóvenes deberían redondear sus conocimientos con lecturas profusas, con análisis y explicaciones que se deriven de lo leído-. el alumno, en cambio, se adiestra en la memorización de fechas, nombres, títulos de libros que no le sirven luego para nada y que olvida rápidamente.

La enseñanza de la literatura, a mi entender, no constituye en muchos casos un ejercicio de aventura y descubrimiento de otros mundos a través de los libros, sino la odiosa memorización y repetición de esos directorios telefónicos que son los manuales de historia literaria. El estudiante es condenado a aprender, siguiendo una secuencia inflexible, los movimientos, escuelas, tendencias, figuras y obras, pero no lee de principio a fin una sola novela, un solo poema. Conoce todos los títulos sin haber leído el contenido de ninguno. Ahora existen las versiones simplificadas de obras, que traen en unas cuantas páginas lo que deseamos saber del argumento, el estilo del autor, las características de los personajes y otras cosas, pero dejan al estudiante tan ignaro como estaba antes de consultarlos. Eso sí, la tarea escolar se cumple y el muchacho obtiene una nota. Creo que la enseñanza de la litera-

Marguerite Yourcenar. op. cit. p.41 
tura siempre ha tenido la deformación de abarcar demasiado todo superficialmente- - cuando lo importante es leer un puñado de obras capitales que nunca olvidaremos. que ampliarán nuestro vocabulario y van a enseñarnos cómo resolver las dificultades de la lectura.

Pero también ocurre que los propios profesores de literatura desconocen las obras y se protegen obligando al estudiante a embotellarse una serie de informaciones inútiles. En consecuencia, se aprende a detestar la literatura y la lectura se convierte en una pesadilla. El estudiante vive preguntando para qué le servirá todo eso que lo fuerzan a leer, porque no sabe todavía que la literatura es un modo de conocimiento único, maravilloso, una forma de enriquecer el intelecto y adquirir una apreciable capacidad analítica y habilidad en el manejo del lenguaje.

Así, un día, huérfanos de lecturas, los jóvenes ingresan a la universidad. Comienzan entonces a "pasar trabajo" con sus cursos de historia, sociología o letras, para desesperación de sus profesores. A los dieciocho años, sin embargo, se está a tiempo todavía para cambiar el rumbo. Lo único que se necesita es un poco de orientación para encontrar el valioso significado de los libros, voluntad para hacer hábito de lectura, tesón para continuarlo y libros. En este proceso, el hogar y la escuela tienen mucho que aportar a la formación integral de las nuevas generaciones.

\section{RECOMENDACIONES PARA UNA BIBLIOTECA PERSONAI.}

\section{BÁSICA}

Han sido muchos los esfuerzos educativos realizados a través de nuestra historia contemporánea para estructurar bibliografías esenciales que contribuyan a una formación personal amplia, independientemente del rumbo profesional que cada individuo decida tomar. Entre nuestros pensadores y maestros, el más ambicioso intento corresponde a Pedro Henríquez Ureña, quien emprendió la ingente tarea, cuando vivía en la Argentina, 
de reunir, por encargo de una prestigiosa casa editoria, las cien obras clásicas de la literatura universal, destinadas a estudiantes de segunda enseñanza, con prólogos y notas escritos por él. Dicha colección abarcó buena parte de los clásicos de siempre, pero quedó incompleta. En materia editorial, el país ha contado con esfuerzos loables para reunir y difundir los valores de nuestras letras, desde la Colección Pensamiento Dominicano; que llenó una época inolvidable, cuando los libros eran baratos y leer constituía una actividad básica en el hogar, hasta la Biblioteca de Clásicos Dominicanos, en la que se pretende recoger nuestras obras fundamentales a partir del siglo XIX.

Para cualquier educador es un verdadero rompecabezas tener que realizar una lista, limitada o extensa, de autores y obras que deben ser leídos y estudiados, para que los educandos adquieran una formación adecuada en materia literaria y otras disciplinas, que luego les permita acceder a niveles profesionales satisfactorios. En el mundo tecnológico de hoy, la formación humanística adquiere una indiscutible validez: no se puede ser buen profesional, si no se tiene una visión global del mundo y sus conquistas culturales; si no se posee un instrumental mínimo con el que podamos trascender los límites de la especialización. Para preparar de manera integral a quienes cursan niveles intermedios de la educación, debería crearse un plan de lecturas graduales y supervisadas que vayan echando la zapata de ese edificio inmenso que constituye el conocimiento humano.

Mientras se van asimilando las lecturas de los grandes maestros universales de todos los tiempos, en ediciones comentadas y prologadas por autoridades en la materia - existen colecciones de todos conocidas en la actualidad, como Cátedra, por ejemplo, que hace énfasis en los clásicos españoles, a partir de los místicos del Siglo de Oro-, conviene ir penetrando en esa riquísima cantera de autores y obras de Hispanoamérica y la República Dominicanıa. Junto a la impresionante obra de José Martí y Rubén Darío, dos maestros fundacionales de la poesía en lengua espa- 
ñola, cuya impronta modernista se impuso en todo el ámbito del idioma, es necesario conocer también los mejores libros de Gabriela Mistral, Pablo Neruda y César Vallejo, tres grandes poetas hispanoamericanos del siglo veinte que toda persona que se precie de instruida debe leèr. A través de sus poemas no sólo accederemos a una nueva visión de nuestro hemisferio, sino también a una sensibilidad y un decir completamente distintos de los que prevalecieron durante el romanticismo decimonónico, época de autores importantes que buscaban nuestras esencias por caminos distintos, como José Hernández, Domingo Faustino Sarmiento, Jorge Isaacs, Manuel de Jesús Galván y Juan Zorrilla de San Martín.

Y como la poesía es el área fuerte de las letras dominicanas, es preciso que los planes de lectura contengan las obras cimeras de nuestros vates principales. Tenemos por lo menos una docena de figuras muy sólidas cuya poesía es el mejor camino para conocernos a fondo. No es cierto que la poesía sea incomprensible ni esté pasada de moda, pues mientras haya imaginación y sentimiento habrá poesía, sino que nos faltan estímulos para penetrar en sus secretos, y seguramente tiempo para sentarnos con calma a disfrutar de ella.

Como he dicho en otra parte, nuestra poesía recorre el siglo que ahora termina y deja un perdurable legado de voces y obras. Hecha de palabras y de ritmo, de imágenes y metáforas, ella es la interpretación, oral o escrita, grande o pequeña, de nuestras esencias. Todo lo que somos y hemos sido; las verdades soñadas y las vividas; el mito, la fe, las creencias; el deseo, el amor, y la muerte; las palpitaciones del ser y los laberintos de la conciencia; las conmociones sociales y las incógnitas del porvenir; todo, en fin, se encuentra en nuestra poesía. Creadores de la talla de Salomé Ureña, Domingo Moreno Jimenes, Manuel del Cabral, Pedro Mir, Tomás Hernández Franco, Héctor Incháustegui Cabral, Franklin Mieses Burgos, Freddy Gatón Arce y Manuel Rueda, para sólo citar a unos cuantos, constituyen el punto de partida de cualquier 
indagación sobre nuestra idiosincrasia. Ellos han dicho sobre nuestro pueblo, en unos cuantos libros indispensables. lo que ha requerido miles de páginas de historia nacional.

Vivimos en la época de los apresuramientos, y se dice que no hay tiempo ni "juicio" para leer. Me parece que una magnífica entrada al universo de la literatura podría realizarse a través del cuento, género breve, intenso, maravilloso. capaz de conmovernos y llevarnos a reflexiones profundas. Surgen de inmediato los nombres de Horacio Quiroga, Juan Bosch. Juan Rulfo, Jorge Luis Borges, Adolfo Bioy Casares y Julio Cortázar, grandes maestros del género en este siglo, a los que añadiría los nombres de Mario Benedetti. Augusto Monterroso, Julio Ramón Ribeyro y José Luis González.

La lectura de una novela corta puede convertirse también en una auténtica aventura. Hay novelas que, precisamente por ser obras maestras, no tienen ningún desperdicio. La invención de Morel de Boiy Casares. El túnel de Ernesto Sabato, El acoso de Alejo Carpentier, El astillero de Juan Carlos Onetti. Pédro Páramo de Rulfo, Casas muertas de Miguel Otero Silva. Papeles de Sara de Manuel Rueda. Crónica de una muerte anunciada de Gabriel García Márquez. Coronación de José Donoso. Aura de Carlos Fuentes, y La ciudad y los perros de Mario Vargas Llosa. forman una selección de la mejor narrativa hispanoamericana de este siglo que ningún universitario debería desconocer.

La formación literaria no estaría completa sin la lectura de ensayistas que han marcado el rumbo en diferentes momentos de nuestro devenir histórico. Así, de la mano de Martí conoceremos el fervor del poeta que también fue un gran patriota. ofrendando su vida por la independencia de Cuba. su amada patria. y que dejó semblanzas de otros héroes, como Bolivar y San Martín. que están llenas de vida y amenidad. In la lectura del Ariel de José Enrique Rodó seremos alertados del peligro que representaba el avance norteamericano en América Latina en las primeras décadas del siglo. 
Pedro Henriquez Ureña y Alfonso Reyes, las voces más altas en el México posterior a la revolución. nos ponen en contacto con un ideal humanístico que exalta los ideales de justicia y belleza en una época de convulsiones sociales y políticas. No olvidemos tampoco a Borges, paradigma de perfección en sus cuentos y ensayos, pero ante todo dueño de una mirada aguda y de un decir inigualable que le permite fabular y pensar, habiendo dejado una serie de ensayos literarios que descubren valores ocultos y descifran claves.

Pero de todos los ensayistas de nuestra América en los tiempos que corren, debo señalar la importancia de Octavio Paz, excelente poeta y grandioso pensador que ha sabido esclarecer los enigmas del mundo actual en una prosa que impacta por su claridad y su belleza, su hondura conceptual y su diversidad de enfoques. Puede convencer al lector, haciéndolo partidario de sus posiciones; o logra provocar en él una reacción de desconcierto y escándalo, pero jamás lo deja indiferente. Sabe ser polémico y seductor a un tiempo, introduciéndonos con sutileza en los vericuetos de sus demostraciones, o convirtiendo en apasionada discusión un tema que sólo él sabe reiterar con palabras cada vez distintas. Es un disidente consumado y ha hecho de la controversia su principal instrumento analítico. Desde hace muchos años, Octavio Paz es el escritor hispanoamericano de mayor resonancia continental, no sólo por la vastedad de su obra, sino por sus decisivas contribuciones a la clarificación de los problemas de nuestro tiempo, a partir de la publicación de su obra inicial El laberinto de la soledad.

Por último, hay un campo lleno de atractivos para quien se inicia en la lectura. Se trata de las biografías y memorias. que nos ponen en contacto con la vida y experiencias de autores diversos, dejando en nosotros una serie de enseñanzas. Cuando era un muchacho, ése constituía para mí un filón de motivaciones y estímulos intelectivos. Recuerdo haber leído con gran interés algunos tomos de las Vidas paralelas de Plutarco, unas cuantas bio- 
grafías de Emil Ludwig, de quien no olvido la de Miguel Ángel; y luego, en una sucesión interminable, las de Jesús, Leonardo da Vinci, Napoleón, Tomás Alva Edison, Rubén Darío, o la serie de los grandes músicos, entre muchos otros, y, ya más adulto, haberme deleitado con las memorias de Graham Greene, Tennessee Williams, Marguerite Yourcenar, Alberto Moravia. En cada uno de esos libros está de cuerpo entero la figura del artista. el pensador o el héroe, con sus luces y sombras. dejando en los lectores un sedimento de vivencias e ideas que servirán para guiarnos en nuestro camino por el mundo.

Finalmente, si me piden recomendar algunos libros de este tipo para los lectores de hoy, no podría omitir cuatro o cinco libros que me parecen esenciales. Me refiero a Confieso que he vivido de Pablo Neruda, casi un poema en prosa sobre su vida; el desgarrador testimonio de Isabel Allende contenido en Paula. libro autobiográfico que puede considerarse su mejor obra hasta el momento; El pez en el agua de Mario Vargas Llosa, en el que establece un contrapunto entre su vida y sus ideales políticos; y Adiós, poeta de Jorge Edwards, Ileno de nostalgia y sin las espinas de su Persona non grata.

Deseo concluir con una cita Gianni Rodari, de su libro Gramática de la fantasía, incluida por Fernando Savater en un libro sobre la educación: "El encuentro decisivo entre los chicos y los libros se produce en los pupitres del colegio. Si se produce en una situación creativa, donde cuenta la vida y no el ejercicio, podrá surgir ese gusto por la lectura con el cual no se nace, porque no es un instinto. Si se produce en una situación burocrática, si al libro se lo maltrata como instrumento de ejercitaciones (copias, resúmenes, análisis gramatical, etc.). sofocado por el mecanismo tradicional 'examen-juicio', podrá nacer la técnica de la lectura, pero no el gusto. Los chicos sabrán leer, pero leerán sólo si se les obliga. Y fuera de la obligación. se refugiarán en las historietas -aun cuando sean capaces de lecturas más complejas 
y más ricas-, tal vez sólo porque las historietas se han salvado de la 'contaminación' de la escuela."

\section{BIBLIOGRAFÍA CITADA}

Allende, Isabel. Paula. Barcelona, Plaza \& Janés Editores, 1994.

Bioy Casares, Adolfo. La invención de Morel. Buenos Aires, Emecé Editores, 1972.

Buñuel, Luis. Mi último suspiro. Barcelona, Plaza \& Janés Editores, 1990

Calderón de la Barca. La vida es sueño. Buenos Aires. Kapeluz, 1965.

Carpentier, Alejo. El acoso. Barcelona, Editorial Bruguera, 1980.

Cassou, Juan. El Greco. México, Editorial Nacional, 1957.

Cervantes y Saavedra, Miguel. El ingenioso hidalgo don Quijote de la Mancha. En Obras completas. Madrid, Aguilar, 1965.

Dante Alighieri. La divina comedia. Buenos Aires, Editorial Sopena, 1964

Darío, Rubén. Autobiografía. México, Editorial Latino Americana, 1960.

Darío, Rubén. Poesías completas. Madrid, Aguilar, 1961.

Donoso, José. Coronación Barcelona, Seix Barral, 1962.

Dostoievski, Fedor. Crimen y castigo. En Obras completas, tomo II. Madrid, Aguilar, 1969.

Edwards, Jorge. Adiós, poeta. Barcelona, Tusquets Editores, 1990.

Flaubert, Gustave. Madame Bovary. Madrid, Alianza Editorial, 1974.

Fuentes, Carlos. Aura. En Cuerpos y ofrendas. Madrid, Alianza Editorial, 1972.

García Márquez, Gabriel. Crónica de una muerte ununciada. Bogotá, Editorial La Oveja Negra, 1981.

Goethe, Johann Wolfgang von. Doctor Fausto. Madrid. Espasa-Calpe. 1984.

Góngora, Luis. Soledades. Madrid, Edición, notas y versión de Dámaso Alonso, 1935

\footnotetext{
+ Fernando Savater. El valor de educar. Barcelona, Circulo de I ectores. S A. 1997
} 
Gracián, Baltasar. El arte de la prudencia. Madrid, Ediciones Temas de Hoy, S.A. (T.H.), 1996.

Greene, Graham. Vias de escape. Barcelona, Editorial Argos Vergara, S.A., 1981.

Homero, La lliada. Buenos Aires, Editorial Sopena, 1961.

Homero. La Odisea. Buenos Aires, Editorial Sopena, 1962.

Huxley, Aldous, Contrapunto. Barcelona, Editora y Distribuidora Hispano Americana, S.A., 1979.

Jaspers, Karl. Leonardo como filósofo. Buenos Aires, Eidotiral Sur, 1960. Jones, F.A. Tomás Al a Edison. México, Editora Nacional, 1958.

Kafka, Franz. La metamorfosis. Madrid, Alianza Editorial, 1969.

Ludwig, Emil. Miguel Ángel. Barcelona, Editorial Juventud, 1958.

Mann, Thomas. La montaña mágica. Barcelona. Plaza \& Janés Editores, S.A., 1993.

Maquiavelo, Nicolás. El príncipe. Madrid, Espasa Calpe, Colección Austral, 1964.

Martí, José. Poesia completa Madrid, Alianza Editorial, 1995.

Martí, José. Páginas escogidas. Buenos Aires, Kapelusz. 1959.

Marx, Karl/Engels, Friederich. Manifiesto del Partido Comunista. Moscú, Ediciones en Lenguas Extranjeras, $\mathrm{s} / \mathrm{f}$.

Milton, John. El paraíso perdido Madrid, Espasa-Calpe, 1980.

Moravia, Alberto. El rey está desmudo. Barcelona, Plaza \& Janés Editores, 1982

Muñoz Pérez, Antonio. Gluck. París. Casa Editorial Franco-IberoAmericana, s/f

Neruda, Pablo. Confieso que he vivido. Buenos Aires, Editorial Losada, 1975.

Onetti, Juan Carlos. El astillero. Barcelona, Seix Barral, 1978.

Otero Silva, Miguel. Casas muertas. Barcelona. Seix Barral. 1975.

Ortega y Gasset, José. La rebelión de las masas. Madrid, Revista de Occidente, Colección Arquero, 1964. 
Papini, Giovanni. Historia de Cristo. México, Editorial Diana, S.A.. 1963.

Paz, Octavio. El laberinto de la soledad. México. Fondo de Cultura Económica, 1991.

Paz, Octavio. Tiempo nublado. Barcelona, Seix Barral, 1983.

Proust, Marcel. En busca del tiempo perdido. Madrid, Alianza Editorial. 7 vols., publicados entre 1966 y 1972.

Plutarco, Vidas paralelas. Madrid, Espasa-Calpe, Colección Austral, N os $228,459,818,843,868,918,946,969,993,1019,1043,1095,1123$, 1148.

Rodó, José Enrique. Ariel. México, Editorial Novaro-México, 1957.

Rulfo, Juan. Pedro Páramo. México, Fondo de Cultura Económica, 1971.

Rueda, Manuel. Papeles de Sara. Santo Domingo, Publicaciones del Voluntariado de las Casas Reales, Editora Corripio, 1985.

Sàvater, Fernando. El valor de educar. Barcelona, Círculo de Lectores, S.A. 1997.

Sabato, Ernesto. Antes del fin. Memorias. Barcelona, Seix Barral, 1999.

Sabato, Ernesto. El túnel. Buenos Aires, Editorial Sudamericana, 1974

Shakespeare, William. Obras completas. Madrid, Aguilar, 1965.

Tolstoi, León. Guerra y paz. Barcelona, Castell y Moretón Editores, S.A. 1981.

Vargas Llosa, Mario. El pez en el agua. Memorias. Barcelona, Seix Barral, 1993.

Vargas Llosa, Mario. La ciudady los perros. Barcelona, Seix Barral, 1968.

Williams, Tennessee. Memorias. Barcelona, Editorial Bruguera, S.A., 1983

Yourcenar, Marguerite. Memorias de Adriano. Barcelona. Edhasa, 1983. $9 .{ }^{\text {na }}$ reimpresión.

Zweig, Stefan. Nietszche (La lucha contra el demonio). Barcelona, Editorial Apolo, 1951. 